\title{
Distinct psychopathology of patients who attempted suicide with rodenticide in Taiwan: a comparative study with patients of suicide with paraquat
}

This article was published in the following Dove Press journal:

Psychology Research and Behavior Management

\author{
Chemin $\operatorname{Lin}^{1,2}$ \\ Tzung-Hai Yen ${ }^{2,3}$ \\ Yeong-Yuh Juang ${ }^{4}$ \\ Chin-Pang Lee ${ }^{2,5}$ \\ Shwu-Hua Lee Le $^{2,5}$ \\ 'Department of Psychiatry, Keelung \\ Chang Gung Memorial Hospital, \\ Taoyuan, Taiwan; ${ }^{2}$ School of Medicine, \\ Chang Gung University, Taoyuan, \\ Taiwan; ${ }^{3}$ Department of Nephrology, \\ Clinical Poison Center, Chang Gung \\ Memorial Hospital, Linkou, Taiwan; \\ ${ }^{4}$ Department of Psychiatry, Koo \\ Foundation Sun Yat-Sen Cancer \\ Center, Taipei, Taiwan; ${ }^{5}$ Department \\ of Psychiatry, Linkou Chang Gung \\ Memorial Hospital, Taoyuan, Taiwan
}

Correspondence: Shwu-Hua Lee Department of Psychiatry, Chang Gung Memorial Hospital, 5 Fu-Shin Road, Kwei-Shan, Taoyuan 333, Taiwan

Tel +886 3328 I 200 ext 2439

Fax +886 33280267

Email shlee@adm.cgmh.org.tw
Objective: Rodenticide as a means of suicide has been documented for centuries. However, this method is often discussed in conjunction with other pesticides. Thus, we aimed to focus on patients who committed suicide with rodenticide and compared them with those who used paraquat for suicide, another frequently used yet lethal method, to highlight the different psychopathology of patients who choose rodenticide as their means of suicide.

Methods: A 12-year retrospective chart review was conducted on the medical records of all patients admitted to Chang Gung Memorial Hospital due to attempted suicide by either rodenticide or paraquat. Psychiatric consultation sheets were collected to ascertain the psychiatric comorbidity and the major stressor for suicide, measured by the Social Readjustment Rating Scale. A $\chi^{2}$ test and logistic regression were used for group comparisons.

Results: Seventeen rodenticide and 157 paraquat suicide attempts were identified. Compared with suicides by paraquat, suicides by rodenticide had a more even distribution in the gender ratio but a lower Social Readjustment Rating Scale score $(p<0.001)$. Depressive disorder was the most common diagnosis in suicides by rodenticide and paraquat. However, schizophrenia and psychotic disorder (29.4\%) was the second most common diagnosis and a significant predictor of suicide by rodenticide (odds ratio $=9.21,95 \%$ confidence interval $=1.2-66.07, p=0.027$ ).

Conclusion: High comorbidity of psychosis in suicide by rodenticide warrants disease-specific suicide prevention and additional large-scale research to confirm this association.

Keywords: rodenticide, paraquat, suicide, major depression, schizophrenia

\section{Introduction}

In 2010 , suicide was ranked as the 13th leading cause of death worldwide ${ }^{1}$ and had resulted in nearly 800,000 deaths each year. ${ }^{2}$ However, methods of suicide vary, and understanding the uniqueness of each method helps public awareness and the formulation of individualized strategies for suicide prevention. ${ }^{3}$ Among different methods of suicide, suicide by poisoning is perhaps the most widely used method because pesticide ingestion alone has resulted in $30 \%$ of all suicide deaths worldwide. ${ }^{4}$ However, suicide by poison is a heterogeneous entity as it comprises different poisons, including drug overdoses, pesticides, carbon monoxide, and other various toxins. ${ }^{5}$ For each poison, not only is the ensuing medical treatment different following ingestion but also are both the demographic and underlying psychopathology of those who choose the specific poison for suicide. For example, there is a gender difference in the underlying psychiatric pathology of those who attempt suicide with carbon monoxide intoxication 
by charcoal burning. ${ }^{6}$ This method is more prevalent in urban areas, ${ }^{7}$ which are geographically distinct from traditional rural-based pesticide suicide. ${ }^{8}$ Therefore, a more refined breakdown within suicide by poison should be undertaken as different poisons may entail different suicide prevention plans in general and measures in specific.

Rodenticide (rat poison) has been reported for more than a century as a poison used for committing suicide. ${ }^{9}$ The chief ingredient in rodenticide was warfarin at first, but gradually became 4-hydroxycoumarin derivatives, compounds such as brodifacoum and bromadiolone. ${ }^{10}$ Although series of case reports have been documented over the years, ${ }^{11-14}$ the single largest existing retrospective study comprising 88 patients with intentional rodenticide ingestion was published 15 years ago. ${ }^{14}$ However, this report did not specifically mention whether the psychiatric diagnosis was formally assessed. Moreover, rodenticide is traditionally grouped within the category of pesticides in suicide research, ${ }^{8,15,16}$ making suicide by rodenticide a less-studied method regarding both underlying psychopathology and other relevant patient characteristics. Therefore, it is imperative to have a complete psychiatric evaluation of suicide by rodenticide. ${ }^{17,18}$

Recently, we summarized medical outcomes in a retrospective study on suicide by rodenticide and found major psychiatric illness to be a comorbidity associated with suicide by rodenticide. ${ }^{19}$ Therefore, in the current study, we conducted a concurrent retrospective review of all the psychiatric consultation records of suicide by rodenticide across this period. Concomitant psychiatric consultation records on those of paraquat suicide within the same period were also collected. There are several reasons to include paraquat suicide as a comparator group. Traditionally, they are discussed as a whole because they both use orally ingested poisons. While paraquat has no taste or smell, ${ }^{20}$ those who ingest rodenticide for suicide must endure the aversive taste added during its formulation. ${ }^{21}$ Moreover, paraquat $\left(1,1^{\prime}\right.$-dimethyl4,4'-bipyridinium dichloride) is a widely used herbicide and is notoriously lethal. However, the public is not fully aware of the toxicity of rodenticide, especially under circumstances of human ingestion. Therefore, based on these similarities and differences between the 2 methods, we aimed to both conduct a comparative analysis and examine whether suicide by rodenticide could be seen as a distinct entity, compared with suicide by paraquat.

\section{Methods}

We conducted this study based on the guidelines of the Declaration of Helsinki. The institutional review board from the medical ethics committee of Chang Gung Memorial Hospital approved this study and waived the need for informed consent for this study due to its retrospective design. Data were collected retrospectively from the period from January 2000 to December 2012 for all patients admitted to the Department of Nephrology ward due to rodenticide intoxication after searching the electronic database. After data collection, they were deidentified during the analysis.

A confirmatory medical review was done for this research by examining both the clinical history and laboratory data, specifically including the prothrombin ratio and the international normalized ratio, to ascertain the validity of rodenticide ingestion. We reported the inclusion and exclusion criteria elsewhere. ${ }^{19}$ In total, 25 patients were identified as having rodenticide intoxication during this period. Among them, 8 patients were confirmed as accidental ingestion and were excluded, leaving 17 patients included as suicide attempts as none of them died after treatment.

Under standard care, each suicide attempt was monitored once the patient was admitted through the emergency room because of poison ingestion. Once suicide intent was confirmed or highly suspected, a psychiatric consultation was initiated. We detailed the process of consultation in previous papers. ${ }^{6,22}$ In short, a diagnostic interview was carried out directly with the patient, plus collateral information was gathered from key informants, family members, medical team members, and ambulance records to both verify the act of suicide and aid the final psychiatric diagnosis, based on the Diagnostic and Statistical Manual of Mental Disorders-IV-Text Revision. ${ }^{23,24}$ In all 17 cases of suicide by rodenticide, no one refused the psychiatric consultation request. After the diagnostic interview, all patients presented here confirmed having had the intent to die during the act, thereby fulfilling the definition of a suicide attempt. ${ }^{25,26}$ However, because of the retrospective study design, we did not quantify the suicidality in each patient.

Besides demographic data, we ascertained the cause of suicide from both the consultation and medical record. The causal factor for suicide was categorized and quantified according to the Taiwanese version of the Social Readjustment Rating Scale (SRRS). ${ }^{25,26}$ Underlying medical comorbidity was estimated using the Charlson Comorbidity Index. ${ }^{27}$ We repeated the same process in patients admitted because of paraquat intoxication. One hundred and fifty-seven patients admitted during the same period because of intentional ingestion of paraquat were included for comparison in the current study. However, 7 out of these 157 patients refused psychiatric consultation, leaving 150 in the comparative analysis with suicide by rodenticide. The recruitment process of suicide 
by paraquat is described elsewhere. ${ }^{22}$ We enrolled patients because of paraquat intoxication that was confirmed by blood or urine detection of paraquat. Patients underwent the same psychiatric consultation as described for rodenticide. Unlike rodenticide, paraquat caused a $58 \%$ mortality rate ( 87 patients out of 150 suicide attempts by paraquat).

\section{Statistical analysis}

We reported continuous variables with means and standard deviations and categorical variables with the number of subjects and their percentages. $\chi^{2}$ or Fisher's exact test and Student's $t$-test were used appropriately for categorical or continuous variables to compare suicide by rodenticide with suicide by paraquat. A multivariate logistic regression analysis was also conducted using independent variables (enter method), including age, gender, and all other variables significant in group comparisons, to predict suicide by rodenticide among all subjects from the two groups. Our choice in selecting variables in the model was based on both our hypothesis and the results of a bivariate analysis that different psychiatric diagnoses are linked to different choices of suicide method. Both age and gender were included automatically to control for demographic data, and SRRS was included to adjust for psychosocial stress in each suicidal act. SPSS 16.0 software (SPSS Inc., Chicago, IL, USA) was used for statistical computations.

\section{Results}

Seventeen patients were identified as attempted suicide by rodenticide, while 7 accidentally ingested the poison. There was a significant age difference between those who had intentional ingestion and accidental ingestion (age $=45.8 \pm 20.0$ and $13.8 \pm 16.3$, respectively, $d f=23, t=3.94, p=0.001$ ) as most cases of accidental ingestion occurred in children.

Of the 17 suicide attempts by rodenticide, most of the people were middle-aged and married. Compared with suicide by paraquat, suicide by rodenticide had a more even distribution in gender ratio and a lower SRRS score of the stressor for the current suicide attempt $(p<0.001)$ (Table 1). In the breakdown of these stressors (Table 2), suicide by rodenticide resulted predominantly from personal illness and couples conflict, whereas suicide by paraquat was associated more with financial difficulties, which ranked higher in scores of the SRRS.

The most common psychiatric diagnosis for suicide by rodenticide was depressive disorder (54\%), irrespective of major depressive disorder or dysthymia. However, the second common diagnosis was schizophrenia or psychotic-related disorder (29.4\%); including 4 patients diagnosed with schizophrenia, and 1 had persistent delusions and hallucinations after traumatic brain injury. Individuals who attempted suicide by rodenticide had a higher schizophrenia or psychotic disorder rate but a lower adjustment disorder rate than did individuals who committed suicide using paraquat ( $p=0.002$ and $p=0.032$, respectively) (Table 3 ).

In a multivariable logistic regression model (Table 4), it was revealed that adjustment disorder (odds ratio $[\mathrm{OR}]=0.12$, $95 \% \mathrm{CI}=0.02-0.75)$ schizophrenia or psychotic disorder (OR $=9.21,95 \% \mathrm{CI}=1.2-66.07)$, and SRRS score of stressor for suicide $(\mathrm{OR}=0.73,95 \% \mathrm{CI}=0.63-0.84)$ were significant

Table I Comparison of baseline demographics between suicide by rodenticide and suicide by paraquat $(n=174)$

\begin{tabular}{|c|c|c|c|c|}
\hline Demographic variables & Rodenticide $(n=17)$ & Paraquat $(n=157)$ & $\chi^{2}$ or $t$ & $p$-value \\
\hline Gender, n (\%) & & & 5.06 & $0.030 *$ \\
\hline Male & $9(52.9)$ & $122(77.7)$ & & \\
\hline Female & $8(47.1)$ & $35(22.3)$ & & \\
\hline Age (years), mean $\pm S D$ & $45.8 \pm 20$ & $41.2 \pm 14.9$ & -1.19 & 0.363 \\
\hline Marital status, n (\%) & & & 0.228 & 1.000 \\
\hline Single & $5(29.4)$ & $55(51.9)$ & & \\
\hline Married & $9(52.9)$ & $35(33.0)$ & & \\
\hline Divorced & $2(11.8)$ & $15(14.2)$ & & \\
\hline Widowed & I (5.9) & I (0.9) & & \\
\hline Education, years & $9.0 \pm 1.1$ & $9.3 \pm 3.1$ & 0.56 & \\
\hline Unemployed, n (\%) & $10(58.8)$ & $80(51.0)$ & 0.38 & 0.615 \\
\hline Living alone, $\mathrm{n}(\%)$ & I (5.9) & $19(12.1)$ & 0.58 & 0.697 \\
\hline Concomitant alcohol use, $\mathrm{n}(\%)$ & $3(17.6)$ & $49(30.6)$ & 1.24 & 0.401 \\
\hline Previous suicide attempt, n (\%) & $3(17.6)$ & $45(30.0)$ & 0.932 & 0.406 \\
\hline SRRS of stressor for suicide, mean \pm SD & $59.4 \pm 8.0$ & $66.9 \pm 4.8$ & 5.70 & $0.000 * *$ \\
\hline Charlson Comorbidity Index, mean \pm SD & $2.4 \pm 1.2$ & $1.9 \pm 0.9$ & -1.636 & 0.119 \\
\hline
\end{tabular}

Notes: ${ }^{*} p<0.05,{ }^{*} p<0.001$. Age, education, SSRS, and Charlson comorbidity index were calculated by Student's $t$-test. Abbreviation: SRRS, Social Readjustment Rating Scale. 
predictors for suicide by rodenticide. In other words, schizophrenia or psychotic disorder was associated with higher risk ( 9.21 fold) of suicide by rodenticide. On the other hand, adjustment disorder was associated with lower risk ( 0.12 fold) of suicide by rodenticide. Furthermore, each increment in 1 SRRS score of the stressor for suicide was associated with lower risk ( 0.73 fold) of suicide by rodenticide.

\section{Discussion}

We found that suicide by rodenticide was not different from suicide by paraquat regarding age, marital status, and underlying medical comorbidity, except for a female-predominant gender ratio. Although underlying mental or physical illness

Table 2 Triggers for suicidal act grouped by SRRS, $\mathrm{n}=174$

\begin{tabular}{|c|c|c|}
\hline Triggers for suicidal act ${ }^{\mathrm{a}}$ & Rodenticide & Paraquat \\
\hline Death of spouse, $n(\%)$ & $\mathrm{I}(5.9)$ & 0 \\
\hline Death of parent, $n(\%)$ & 0 & $2(1.3)$ \\
\hline Broke or sharp decline in business, $n(\%)$ & 0 & $23(15.3)$ \\
\hline Financial status change, $\mathrm{n}(\%)$ & 0 & $\mathrm{I}(0.7)$ \\
\hline Divorce, $\mathrm{n}(\%)$ & 0 & $3(2.0)$ \\
\hline Illness, n (\%) & $8(47.1)$ & $54(36.0)$ \\
\hline Mental & $5(29.4)$ & $44(29.3)$ \\
\hline Physical & $3(17.6)$ & $10(6.7)$ \\
\hline Lay-off, n (\%) & I (5.9) & $8(5.3)$ \\
\hline Parent-child conflict, $\mathrm{n}(\%)$ & 0 & $16(10.7)$ \\
\hline Legal problem, n (\%) & 0 & $2(1.3)$ \\
\hline Job change, $n(\%)$ & 0 & $3(2.0)$ \\
\hline Examination, $\mathrm{n}(\%)$ & 0 & I (0.7) \\
\hline Conflict with beaux-parents, $\mathrm{n}(\%)$ & 0 & $\mathrm{I}(0.7)$ \\
\hline Couples conflict, n (\%) & $5(29.4)$ & $24(16.0)$ \\
\hline Move, n (\%) & I (5.9) & 0 \\
\hline Pregnancy, n (\%) & 0 & $\mathrm{I}(4.1)$ \\
\hline Breaking up, n (\%) & I (5.9) & $11(7.3)$ \\
\hline
\end{tabular}

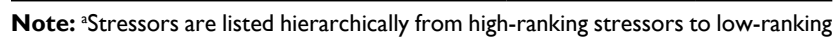
ones.

Abbreviation: SRSS, Social Readjustment Rating Scale. was the major precipitator for suicide in both, suicide by rodenticide was caused by milder stressors, such as couples conflict. Regarding psychiatric comorbidities, depressive disorder was the major diagnosis for both; however, schizophrenia or psychotic disorder was overrepresented in suicide by rodenticide.

The gender ratio in suicide by rodenticide is consistent with the well-observed female-predominant gender ratio for all attempted suicides. ${ }^{28}$ We previously reported male predominance in suicide by paraquat, probably reflecting the fact that men may be the workforce in rural areas with more accessibility to paraquat. $^{22}$ The gender composition of each method of suicide transcends the different causes of suicide in the individual group. Both types of suicide were triggered by underlying health problems and intimate partner conflicts, which was also observed in other literature on suicide. ${ }^{29}$ However, as financial difficulty was found more frequently among males who committed suicide, ${ }^{30}$ it is reasonable that it constitutes a bigger part of the triggers in suicide by paraquat, where the subjects were predominantly male.

The principal psychiatric diagnosis for both types of suicide was depressive disorder, since undertreated depression was the most frequently found mental illness in suicide ${ }^{31}$ and suicide was more prevalent among those with mood disorders. ${ }^{32}$ Our finding of no difference in the rate of depressive disorder between the 2 groups supports previous findings that depression is not linked to any specific type of suicide. ${ }^{33}$ Also, it strengthens the need to treat mood disorders because better treatment leads to lower suicide rates. ${ }^{34}$

Although the triggers for suicide by rodenticide appeared milder than triggers for suicide by paraquat, there was a lower rate of adjustment disorder but a higher rate of schizophrenia or psychotic disorder in suicide by rodenticide. The high rate

Table 3 Differences in psychiatric diagnoses between suicide by rodenticide and paraquat $\left(n=167^{a}\right)$

\begin{tabular}{|c|c|c|c|c|}
\hline Diagnosis & $\begin{array}{l}\text { Rodenticide } \\
(n=17)\end{array}$ & Paraquat $(n=150)^{a}$ & $\chi^{2}$ & $p$-value \\
\hline Depressive disorder, $\mathrm{n}(\%)$ & $9(52.5)$ & $77(51.3)$ & 0.02 & 0.900 \\
\hline Major depressive disorder & $5(29.4)$ & $37(24)$ & 0.18 & 0.768 \\
\hline Dysthymia & $4(23.5)$ & $40(26.7)$ & 0.08 & 1.000 \\
\hline Adjustment disorder, $\mathrm{n}(\%)$ & $2(3.2)$ & $15(14.4)$ & 5.43 & $0.020 *$ \\
\hline Bipolar depression, $\mathrm{n}(\%)$ & 0 & $4(2.7)$ & 0.46 & 1.000 \\
\hline Schizophrenia or psychotic disorder, $n(\%)$ & $5(29.4)$ & $6(4.0)$ & 16.0 & $0.002^{* *}$ \\
\hline \multicolumn{5}{|l|}{ Substance use disorder, $\mathrm{n}(\%)$} \\
\hline Alcohol & $3(17.6)$ & $36(24.0)$ & 0.34 & 0.765 \\
\hline Heroin & 0 & II (7.3) & 1.34 & 0.606 \\
\hline Amphetamine, $\mathrm{n}(\%)$ & I (5.9) & $16(10.7)$ & 0.38 & 1.000 \\
\hline Benzodiazepine, $\mathrm{n}(\%)$ & 0 & $2(1.3)$ & 0.23 & 1.000 \\
\hline
\end{tabular}

Notes: ${ }^{a}$ Seven suicide attempts by paraquat refused psychiatric consultation, leaving 150 with formal $p s y c h i a t r i c ~ d i a g n o s e s, ~ * p<0.05, * * p<0.0$ I. 
Table 4 Multivariate regression analysis for suicide by rodenticide among all individuals who attempted suicide $(n=174)$

\begin{tabular}{llll}
\hline Diagnosis & OR & $\mathbf{9 5 \% ~ C l ~}$ & p-value \\
\hline Age (each increment of I year) & 1.03 & $0.99-1.08$ & 0.124 \\
Female gender & 3.16 & $0.83-12.07$ & 0.093 \\
$\begin{array}{l}\text { Adjustment disorder (yes) } \\
\text { Schizophrenia or psychotic disorder }\end{array}$ & 0.12 & $0.02-0.75$ & $0.023^{*}$ \\
$\begin{array}{l}\text { (yes) } \\
\text { SRRS score of stressor for suicide }\end{array}$ & 0.73 & $0.63-66.07$ & $0.027^{*}$ \\
(each increment of I score) & & & \\
\hline
\end{tabular}

Note: $* p<0.05, * * p<0.001$.

Abbreviations: $\mathrm{Cl}$, confidence interval; OR, odds ratio; SRRS, Social Readjustment Rating Scale.

of psychosis in suicide by rodenticide is intriguing. There is a need to explore what underlies the method of choice for suicide in schizophrenia. For example, jumping from a height is the most frequently chosen method by patients with schizophrenia, ${ }^{33,35,36}$ possibly because they have restrained cognitive function and impulsively resort to gravity as the most straightforward method..$^{33}$ Following the same logic, the high rate of psychosis in suicide by rodenticide may be caused by easy accessibility to rodenticide in household settings for low-functioning schizophrenic patients as more complicated or planned methods are not preferred. However, this does not fully explain why psychotic patients choose rodenticide more among all the available poisons, including paraquat and other pesticides. Bizarre reasons secondary to psychosis have been reported to influence the choice of suicide method behind psychotic patients. ${ }^{37}$ Notably, "ego-dystonic" suicide ideation is particularly related to psychotic depression, ${ }^{38}$ meaning some "unwanted" or "irrational" urge precipitating the act. Also, every suicide method should be put under the context of sociocultural environment, ${ }^{39}$ for example, "rat" is culturally salient (eg, it is ranked first among 12 signs of the Chinese zodiac with the connotation of high fertility). All these may play a role in the decision to employ rodenticide for suicide in psychotic patients. Further studies are warranted on the reasons for their preference for selecting this method.

While we aimed to examine the characteristics of those who attempted suicide by rodenticide by comparison with suicide by paraquat, several methodological limitations need to be addressed. Since this was a retrospective study, a routine psychiatric consultation procedure was not performed that asked the question of why people chose a particular method at that time, thereby limiting our ability to interpret our results further. Furthermore, although we know that personality plays an important role in suicidal behavior, ${ }^{40}$ proper diagnosis of personality is not feasible during a 1-time consultation. Moreover, our participants were inpatients from a single research hospital, and our sample size was limited. Nevertheless, our study spanned a 12-year period with complete psychiatric assessment, ensuring the validity of the diagnosis. Last but not the least, we only listed these predetermined variables in our logistic regression. However, other factors (such as personality, suicidality, or depression severity) were not incorporated in the model due to our study design. Our findings provide direction for future research to replicate similar results in a larger sample. More detailed exploration of the reasons for choosing a particular method for suicide is warranted to design more individualized suicide prevention programs tailored to meet the needs of specific patients.

\section{Conclusion}

Rodenticide is not a rare method of suicide, despite being not as frequent or lethal as suicide by paraquat. Nevertheless, it can result in serious medical consequences related to the increased tendency of bleeding. ${ }^{19}$ We have found that the majority of attempted suicides by rodenticide cases are not different from their counterparts who used paraquat, regarding demographic composition or prevalence of depressive disorder. However, those diagnosed with schizophrenia or psychotic disorder tended to adopt rodenticide more as the method of suicide. This finding has clinical implications since restricting or removing rodenticide can be an important approach to the prevention of suicide particularly in patients with schizophrenia or related psychotic disorders at risk for suicide.

\section{Author contribution}

C Lin, TH Yen, YY Juang, and SH Lee conceptualized and designed the study; $\mathrm{C}$ Lin and TH Yen acquired the data; $\mathrm{C}$ Lin and CP Lee analyzed and interpreted the data; $\mathrm{C} \mathrm{Lin,} \mathrm{TH}$ Yen, and CP Lee; drafted the manuscript C Lin, TH Yen, YY Juang, CP Lee, and SH Lee critically revised the manuscript. All authors contributed toward data analysis, drafting and critically revising the paper and agree to be accountable for all aspects of the work.

\section{Disclosure}

The authors report no conflicts of interest in this work.

\section{References}

1. Wang H, Dwyer-Lindgren L, Lofgren KT, et al. Age-specific and sex-specific mortality in 187 countries, 1970-2010: a systematic analysis for the Global Burden of Disease Study 2010. Lancet. 2012;380(9859):2071-2094.

2. Prince M, Patel V, Saxena S, et al. No health without mental health. Lancet.2007;370(9590):859-877.

3. Mann JJ, Apter A, Bertolote J, et al. Suicide prevention strategies: a systematic review. JAMA. 2005;294:2064-207. 
4. Gunnell D, Eddleston M, Phillips MR, Konradsen F. The global distribution of fatal pesticide self-poisoning: systematic review. BMC Public Health. 2007;7:357.

5. Henderson JP, Mellin C, Patel F. Suicide - a statistical analysis by age, sex and method. J Clin Forensic Med. 2005;12(6):305-309.

6. Lin C, Yen TH, Juang YY, et al. Comorbid psychiatric diagnoses in suicide attempt by charcoal burning: a 10-year study in a general hospital in Taiwan. Gen Hosp Psychiatry. 2012;34(5):552-556.

7. Chang SS, Gunnell D, Wheeler BW, Yip P, Sterne JA. The evolution of the epidemic of charcoal-burning suicide in Taiwan: a spatial and temporal analysis. PLoS Med. 2010;7(1):e1000212.

8. Phillips MR, Yang G, Zhang Y, Wang L, Ji H, Zhou M. Risk factors for suicide in China: a national case-control psychological autopsy study. Lancet. 2002;360(9347):1728-1736.

9. Mowat D. Suicide from rat poison. Lancet. 1891;138:1387-1388

10. Chua JD, Friedenberg WR. Superwarfarin poisoning. Arch Intern Med. 1998;158(17):1929-1932.

11. Swigar ME, Clemow LP, Saidi P, Kim HC. "Superwarfarin" ingestion: a new problem in covert anticoagulant overdose. Gen Hosp Psychiatry. 1990;12(5):309-312.

12. Chong LL, Chau WK, Ho CH. A case of "superwarfarin" poisoning. Scand J Haematol. 1986;36(3):314-315.

13. Holmes RW, Love J. Suicide attempt with warfarin, a bishydroxycoumarin-like rodenticide. J Am Med Assoc. 1952;148(11):935-937.

14. Curcić M, Dadasović J. [Suicide and attempted suicide with rodenticides from 1968 to 2000]. Med Pregl. 2001;54(5-6):256-260. English Abstract. Croatian.

15. Law S, Liu P. Suicide in China: unique demographic patterns and relationship to depressive disorder. Curr Psychiatry Rep. 2008;10(1):80-86

16. Mars B, Burrows S, Hjelmeland H, Gunnell D. Suicidal behaviour across the African continent: a review of the literature. BMC Public Health. 2014;14:606.

17. King N, Tran MH. Long-acting anticoagulant rodenticide (superwarfarin) poisoning: a review of its historical development, epidemiology, and clinical management. Transfus Med Rev. 2015;29)(4):250-258.

18. Wagenaar BH, Raunig-Berhó M, Cumbe V, Rao D, Napúa M, Sherr K. Suicide attempts and deaths in Sofala, Mozambique, from 2011 to 2014 : who, where, and from what. Crisis. 2016;37(6):445-453.

19. Yu HY, Lin JL, Fu JF. Outcomes of patients with rodenticide poisoning at a far east poison center. Springerplus. 2013;2:505.

20. Pomeroy A. Biochemical Mechanisms of Paraquat Toxicity. New York: Elsevier; 2012.

21. Mason JR, Reidinger RF, Stewart CN. Profiling, mimicking and masking the flavor of a selected rodenticide. Physiol Behav. 1985;35(1): 127-134.

22. Lin C, Yen TH, Juang YY, Lin JL, Lee SH. Psychiatric comorbidity and its impact on mortality in patients who attempted suicide by paraquat poisoning during 2000-2010. PLoS One. 2014;9(11):e112160.
23. Wulsin LR, Vaillant GE, Wells VE. A systematic review of the mortality of depression. Psychosom Med. 1999;61(1):6-17.

24. American Psychiatric Association. Diagnostic and Statistical Manual of Mental Disorders. 4th ed, revised. Washington, DC: American Psychological Association Press; 2000.

25. Holmes TH, Rahe RH. The social readjustment rating scale. J Psychosom Res. 1967;11(2):213-218.

26. Pai L, Wen HC, Lu RB, Kuo ML. Revision of assessment chart for stressful events of adult life. Chinese J Mental Health. 1987;3:195-205.

27. Charlson ME, Pompei P, Ales KL, MacKenzie CR. A new method of classifying prognostic comorbidity in longitudinal studies: development and validation. J Chronic Dis. 1987;40(5):373-383.

28. Mościcki EK. Gender differences in completed and attempted suicides. Ann Epidemiol. 1994;4(2):152-158.

29. Schiff LB, Holland KM, Stone DM, et al. Acute and chronic risk preceding suicidal crises among middle-aged men without known mental health and/or substance abuse problems. Crisis. 2015;36:304-315.

30. Rocchi MBL, Sisti D, Miotto P, Preti A. Seasonality of suicide: relationship with the reason for suicide. Neuropsychobiology. 2007;56(2-3): 86-92.

31. Oquendo MA, Malone KM, Ellis SP, Sackeim HA, Mann JJ. Inadequacy of antidepressant treatment for patients with major depression who are at risk for suicidal behavior. Am J Psychiatry. 1999;156(2): 190-194.

32. Mattisson C, Bogren M, Brådvik L, Horstmann V. Mortality of subjects with mood disorders in the Lundby community cohort: a follow-up over 50 years. $J$ Affect Disord. 2015;178:98-106.

33. Huisman A, van Houwelingen CAJ, Kerkhof AJFM. Psychopathology and suicide method in mental health care. $J$ Affect Disord. 2010;121(1-2):94-99.

34. Gibbons RD, Hur K, Bhaumik DK, Mann JJ. The relationship between antidepressant medication use and rate of suicide. Arch Gen Psychiatry. 2005;62(2):165-172.

35. Nielssen O, Glozier N, Babidge N, et al. Suicide attempts by jumping and psychotic illness. Aust N Z J Psychiatry. 2010;44(6):568-573.

36. Chen YY, Lee MB, Chang CM, Liao SC. Methods of suicide in different psychiatric diagnostic groups. J Affect Disord. 2009;118(1-3): 196-200.

37. Berman AL, Silverman MM, Bongar BM. Comprehensive Textbook of Suicidology. New York: Guilford Press; 2000:296.

38. Brådvik L, Berglund M. Antidepressant therapy in severe depression may have different effects on ego-dystonic and ego-syntonic suicidal ideation. Depress Res Treat. 2011;2011:896395.

39. Wu KC, Chen YY, Yip PS. Suicide methods in Asia: implications in suicide prevention. Int J Environ Res Public Health. 2012;9:1135-1158.

40. Brezo J, Paris J, Turecki G. Personality traits as correlates of suicidal ideation, suicide attempts, and suicide completions: a systematic review. Acta Psychiatrica Scandinavica. 2006:113(3):180-206.
Psychology Research and Behavior Management

\section{Publish your work in this journal}

Psychology Research and Behavior Management is an international, peerreviewed, open access journal focusing on the science of psychology and it application in behavior management to develop improved outcomes in the clinical, educational, sports and business arenas. Specific topics covered in the journal include: Neuroscience, memory and decision making; Behavior

\section{Dovepress}

modification and management; Clinical applications; Business and sport performance management; Social and developmental studies; Animal studies. The manuscript management system is completely online and includes a very quick and fair peer-review system, which is all easy to use. Visit http://www. dovepress.com/testimonials.php to read real quotes from published authors. 